\title{
Maternal Separation Affects Mothers' Affective and Reproductive Behaviors as Well as Second Offspring's Emotionality
}

\author{
R. Bousalham, B. Benazzouz, A. El Hessni, A. Ouichou, A. Mesfioui \\ Laboratory of Genetic, Neuroendocrinology and Biotechnology, Faculty of Sciences, Ibn Tofail University, Kenitra, Morocco \\ Email: rim6030@hotmail.com
}

Received May 27, 2013; revised June 28, 2013; accepted July 14, 2013

Copyright (C) 2013 R. Bousalham et al. This is an open access article distributed under the Creative Commons Attribution License, which permits unrestricted use, distribution, and reproduction in any medium, provided the original work is properly cited.

\begin{abstract}
Daily separation of rat pups from their mothers while the preweaning period has an impact on behavior and stress response of pups. We hypothesized that maternal separation may create a depression-like state in mother rats from which we separate the rat pups and decrease their reproductive function and fertility. Also, we aimed to evaluate the transmission degree of depression and anxiety across generations. Females aged 3 months were divided in two groups of 10 rats each. After a first mating and a first parturition, we conducted maternal separation $3 \mathrm{~h}$ during 22 days for the experienced group while the control group mothers kept their pups. At 4 months of age, females underwent behavioral tests and a second mating. Second generation's pups were also subjected to behavioral tests. Behavioral tests showed that mothers which experienced separation were more depressive and anxious than control ones, also they had a lower litter size. Rats pups of the second generation whose mothers experienced maternal separation also revealed behavior changes akin to depression and anxiety. Thus, maternal separation causes depressive and anxious-like states on mother rats which experienced separation and has an impact on their litter size. Also, consequences of maternal separation seem to last throughout generations.
\end{abstract}

Keywords: Maternal Separation; Affective Disorder; Mothers' Rat; Reproduction; Offspring of Second Generation

\section{Introduction}

Precocious chronic stress during early life is known to produce a variety of long-lasting effects that may contribute to future psychiatric disorders. However, its potential to affect reproductive capacities and induce depression and anxiety across generations has not been deeply tested.

Etiology and pathophysiology of those affective disorders remain hard to elucidate despite a lot of advances in neurobiology which lead to recent findings as disturbance in intracellular signaling in brain circuits or changes in gene sequence or expression. Enhancing the basic knowledge about affective disorder is contingent on availability of appropriate disease models.

Animal models of chronic stress constitute valuable tools by which to investigate the behavioral, endocrine and neurobiological changes underlying stress-related psychopathologies [1], such as major depression and anxiety. Three general strategies to develop stress-related animal models have been adopted: genetic manipulation, selective breeding for extremes in a particular behavioral phenotype and environmental manipulations.

To reproduce as closely as possible the circumstances known to foster diseases in humans, many experimental animal models have been developed. However, animal models based on social stressors, such as disruptions of attachment relationship between mother and her pups are the most documented. The relationship between the mother and the newborn rat is of fundamental importance in all species. In the harmonious development, the mother serves as a link between the first environment and animal development; maternal separation could therefore lead to adverse consequences [2].

Indeed, children who faced emotional and physical neglect or abuse showed behavior problems, reduced positive affect expression, difficulty with emotion regulation and social impairments. Also, emotional effects include increased negativity and fearfulness and behavior problems as insecure attachments [3].

The impact of maternal separation on Wistar rats pups 
is well studied. In our previous studies, we demonstrated that 3 hours maternally separated rat pups during the preweaning period develop a depressive and an anxiouslike behaviors (unpublished data). However, effects of maternal separation on mother rats and rat pups of a second generation have not been studied in depth.

We hypothesized, on one hand, that separation-induced depression and anxiety affect mothers' rat and cause behavioral perturbations and reproduction trouble. On the other hand, we examined consequences of maternal separation in a second generation of rat pups whose mothers were subjected to maternal separation.

To test this hypothesis, we made use of behavioral test (Open field test, Elevated Plus Maze and Forced Swim test) and examination of litter size.

\section{Methods}

\subsection{Animals}

All experimental procedures were performed according to the NIH Guide for the Care and Use of Laboratory Animals. The animals used in this study are rats from the wistar strain. They were born, bred and housed on a 12 hlight $/ 12 \mathrm{~h}$ dark cycle, $50 \%$ to $60 \%$ humidity and at a standard temperature $21^{\circ} \mathrm{C} \pm 1{ }^{\circ} \mathrm{C}$. Water and food were provided ad libitum.

\subsection{Procedure}

After the first mating and 22 days of gestation, female rats (3 months of age) gave birth to their first litters. Groups were randomly shared out into:

Control mothers group $(\mathrm{N}=10)$ : composed of mothers who kept their pups throughout the duration of weaning (22 days).

Experimental mothers group $(\mathrm{N}=10)$ : composed of mothers whose pups were removed for 3 hours each day for 22 days.

Pups were daily removed from dams' cages from $1^{\text {st }}$ day of birth to $22^{\text {nd }}$ day post-partum and every pup was disposed in a pot whose bottom was covered with a paper towel. Mothers were also shifted from the dam cage and placed in another cage.

At 4 months of age, these mothers were submitted to behavioral tests and were mated again to males.

We composed four groups from the litters of the second mating; those rats underwent behavioral tests at one month of age:

Male $(\mathrm{N}=5)$ and female $(\mathrm{N}=5)$ descendants of control mothers;

Male $(\mathrm{N}=5)$ and female $(\mathrm{N}=5)$ descendants of mothers previously submitted to maternal separation (Experimental mothers group).

\subsection{Behavioral Testing}

\subsubsection{Open Field Test (OF)}

The investigatory behavior was tested in a wooden made apparatus $(100 \mathrm{~cm} \times 100 \mathrm{~cm})$. As previously reported [4], it was enclosed with $40 \mathrm{~cm}$ high walls and placed under strong illumination ( $100 \mathrm{~W}, 2 \mathrm{~m}$ above the apparatus). The area was divided into 25 squares $(20 \mathrm{~cm} \times 20 \mathrm{~cm})$, defined as 9 central and 16 peripheral squares. At the beginning of the 10-min test, the animal was placed in the center of the apparatus and its behavior was videotaped for subsequent analysis. The device was cleaned after each individual rat session. The quantified parameters were the time spent in the center of the area and the number of returns to the nine square central sections. Central perimeter residence time is used as measure of anxiety [5]. The number of returns to the central area is also an indicator of the emotional reactivity [4]. The central area of a novel environment is anxiogenic and aversive and the behavioral inhibition appears therefore as an avoidance behavior towards the central zone of the open field [6]. The apparatus was cleaned between each examination using $70 \%$ ethyl alcohol.

\subsubsection{Elevated Plus Maze Test (EPM)}

The EPM is an ethological model of anxiety in rodents provoked by the novelty and repulsion as a result of elevation and illumination of the maze [7]. This test is based on the creation of a conflict between the exploratory drive of the rat and its innate fear of open and exposed areas; it has been validated for the detection of emotional responses to anxiogenic and anxiolytic substances [8]. Thus, increased open-arms exploration indicates reduced anxiety-related behavior. The EPM consists of a wooden plus-shaped platform elevated $70 \mathrm{~cm}$ above the floor. Two of the opposing arms $(50 \mathrm{~cm} \times 10 \mathrm{~cm})$ are closed by $40 \mathrm{~cm}$ high side and end walls, having an open roof. In order to avoid fall, the other two arms (open arms) were surrounded by $0.5 \mathrm{~cm}$ high edge, the four arms had at their intersection a central platform $(10 \mathrm{~cm} \times 10 \mathrm{~cm})$. A $100-\mathrm{W}$ lamp was placed exactly over the central platform. At the beginning of the test, the rats were placed on the central area of the maze facing an open arm. The following parameters of anxiety-related behavior were measured during the $5 \mathrm{~min}$ testing period: 1 ) entries into open arms, 2) time spent on the open arms, 3) and number of full entries into the arms. Decreased anxiety-like behavior is illustrated by a significant statistical increase of parameters in open arms (time and/or entries). Although entries in closed arms and total entries reflect the motor component of the exploratory activity, to eliminate any lingering olfactory cues, the apparatus was cleaned between each examination using $70 \%$ ethyl alcohol. 


\subsubsection{Forced Swim Test (FST)}

The method followed was that described by Porsolt et al., [9]. To assess depressive-like responses, rats were individually placed in a cylinder (height $=50 \mathrm{~cm}$; diameter $=$ $30 \mathrm{~cm})$ containing $27 \mathrm{~cm}$ water $\left(22^{\circ} \mathrm{C}\right)$ from which they could not escape. The rats were placed in the water for 5 min and the duration of immobility was measured. The latency to the first bout of immobility was also recorded starting immediately after placing the rats in the cylinders. A rat was judged immobile when it ceased all active behaviors (i.e. struggling, swimming and jumping) and remained passively floating or making minimal movements necessary to maintain the nostrils above water. High percent time floating is interpreted as an increased depressive-like response.

\subsection{Data Analysis}

To determine the differences between control and experimental groups, statistical analysis was performed by analysis of variance (ANOVA). The comparison of the means and their ranking was realized by the Duncan test whenever the analysis of variance showed significant differences.

Differences were considered significant when $\mathrm{p}<0.05$, very significant when $p<0.01$ and highly significant when $\mathrm{p}<0.001$.

\section{Results}

\subsection{Mother Rats}

\subsubsection{Behavioral Test}

Table 1 shows performances of control and experimental groups of mothers rats in the three behavioral tests used in this study.

Immobility time in the FST was significantly affected by separation experience $(p=0.0001)$. Indeed, Mothers that had been daily separated from their pups for $3 \mathrm{~h}$ per day during 22 days showed a highly significant increase in time of immobility in the FST than mothers of the control group. This indicates a great depression-like response.

In one hand, maternal separation very significantly affected the time spent in open arms, mothers of the experimental group spent less time visiting the open arms comparatively to control mothers which stay more. In another hand, maternal separation did affect neither number of entries in open arms nor total number of entries in all arms.

Moreover, maternal separation significantly affected time spent in the central area of the OF test, also it very significantly increase number of returns in the central area. Indeed, mothers having experienced separation spent less time in the central area and visited it less frequently. Number of straightening and excrements were not significantly affected by maternal separation.

The performances realized by the rats in the EPM and the OF shown an anxious-state in the experimental group. However, the depression-state is more pronounced as stated by the results of the FST.

\subsubsection{Examination of Litter Size after a Second Parturition}

Table 2 shows the litter size of mothers belonging to controls and experimental groups. On one hand, comparison of litter sizes of control groups after two consecutive parturitions showed no statistically significant difference. This indicates that the age of the mothers had no influence on litter size since both mating were held a month apart.

On the other hand, maternal separation affected very significantly the number of pups after a second parturition of experimental group as shown by Table 2 . The experimental group's litter size became lower than the

Table 1. Performance of mother rat in behavioral tests. Times are measured in seconds.

\begin{tabular}{|c|c|c|c|c|c|}
\hline \multirow[b]{2}{*}{ Parameter of Behavioral Test } & \multicolumn{2}{|c|}{ Control group } & \multicolumn{2}{|c|}{ Experimental group } & \multirow{2}{*}{$\mathrm{p}$} \\
\hline & Mean & Standard Deviation & Mean & Standard Deviation & \\
\hline Time of immobility (FST) & 15.4 & 5.12 & 59.5 & 28.71 & $\mathrm{p}=0.0001^{* * *}$ \\
\hline Number of entries in open arms (EPM) & 4.3 & 1.49 & 3 & 2.16 & N.S \\
\hline Time spent in open arms (EPM) & 64.30 & 14.57 & 24.9 & 35.23 & $\mathrm{p}<0.05^{* *}$ \\
\hline Total number of entries in all arms (EPM) & 8.4 & 2.36 & 6.4 & 3.37 & N.S \\
\hline Time spent in central area (OF) & 65 & 38.33 & 27.8 & 17.68 & $0.01<\mathrm{p}<0.05^{*}$ \\
\hline Number of returns in central area $(\mathrm{OF})$ & 6.6 & 3.3 & 3.1 & 1.91 & $\mathrm{p}<0.05^{* *}$ \\
\hline Number of straightening (OF) & 7.1 & 4.84 & 4.7 & 1.33 & N.S \\
\hline Number of Excrements (OF) & 2 & 1.49 & 2.4 & 1.5 & N.S \\
\hline
\end{tabular}

p: Probability; NS: Non significant; ${ }^{*}$ : Significant; ${ }^{* *}$ : Very significant; ${ }^{* * *}$ : Highly significant. 
Table 2. Comparison of litter sizes' of control and experimental group.

\begin{tabular}{|c|c|c|c|c|c|c|c|c|c|}
\hline \multicolumn{4}{|c|}{ Control Group } & \multirow{3}{*}{$\mathrm{p}$} & \multicolumn{4}{|c|}{ Experimental Group } & \multirow{3}{*}{$\mathrm{p}$} \\
\hline & First Litter & & Second Litter & & \multicolumn{2}{|r|}{ First Litter } & \multicolumn{2}{|r|}{ Second Litter } & \\
\hline Mean & Standard Deviation & Mean & Standard Deviation & & Mean & Standard Deviation & Mean & Standard Deviation & \\
\hline 9.7 & 2.54 & 10 & 1.15 & N.S & 10.2 & 2.29 & 7 & 2.4 & $\mathrm{p}<0.05^{* *}$ \\
\hline
\end{tabular}

p: Probability; NS: Non significant; ${ }^{* *}$ : Very significant.

size litter that was obtained before maternal separation.

\subsection{Offspring of the Second Generation}

\section{Submission of Rats Pups of the Second Generation to Behavioral Tests (Table 3)}

Male and female one month aged rats (experimental group) tested here are descendants from a second parturition of mothers previously described as depressed and anxious, their performances were compared to those of control one month aged rats (control group) from control mothers.

Descendants rats from depressed and anxious mothers showed, respectively for male and female, a very and a high significant increase in time of immobility in the FST than control rats. This demonstrates a depression-like state in male and in female rats. Furthermore, gender influences significantly the immobility time $(0.01<\mathrm{p}<$ 0.05 ) and female rats ceased all active behaviors more often than males. Immobility time in FST test was the only sex-dependent variable.

Both male and female rats from experimental group spent more time in open arms of the EPM test than rats from control group. Moreover, only male rats from experimental group showed a significant increase in number of returns to the central area of the OF.

Rats' performances in EPM and OF tests revealed an anxious-state less marked than the depressive-state.

Environmental stressors, as maternal separation, can lead to both anxiety and depression that are considered as affective disorder. While the effect of maternal separation in rat pups of a first generation is well studied, we demonstrated here that mothers exhibited depressive and anxious behaviors and these states seem to be transmitted to a second generation of pups.

\section{Discussion}

The results reported here describe a form of depression and anxiety, induced by disruptions of attachment relationships.

Firstly, we demonstrated that mothers subjected to maternal separation showed high levels of depressive like-behavior and moderated anxious state.

Indeed, most studies have concentrated on the effect of maternal separation on pup behavior and physiology with little attention being paid to the impact on mothers. Nonetheless, Boccia et al., [10] demonstrated that mothers subjected to long maternal separation exhibited more immobility and fewer escape attempts than non-separated mothers. These results suggest that long maternal separation induces a depression-like state and a reduction on mother nursing behavior (a decrease of licking that pups receive from mothers).

Thus, separation of pups from dam is also very stressful for the mothers and this is reflected by increasing plasma corticosterone, decreasing plasma prolactin and heavier adrenals which are a marker of chronic stress [11]. These observations suggest that prolonged separation may evoke emotional stress to the dams, elevate plasma stress hormones which alter hypothalamic-pituitary-adrenal activity and therefore may predispose to depression and anxiety-like behaviors [12].

Afterwards, we showed that the litter size of mothers' rats which underwent maternal separation had significantly decreased. This finding states an eventual crosstalk between the reproductive system and the pathophysiological circuits underlying affective disorders.

Indeed, clinical studies have demonstrated that rates of depression increase when estrogen (an essential hormone at all stages of gestation) levels decline such as occurrences surrounding menses, as well as during pregnancy, the postpartum period, and menopause [13].

Estrogen has an essential function in HypothalamoPituitary-Adrenal (HPA) axis regulation through: direct effects on the hypothalamus; modulation of estrogen response elements within the Corticotropin Releasing Hormon gene [14] and modulation of glucocorticoid receptors in the anterior pituitary, hypothalamus, and hippocampus $[15,16]$.

Thus, we could state that when estrogen level decreased, affective disorders were set as a result of HPA axis dysfunctions and reproductive troubles that followed leading to a small litter size.

After a second parturition, depressed and anxious mothers which experienced maternal separation gave birth to descendant with an obvious depressive like-state as shown by long time of immobility in the forced swim test and a barely perceptible anxious state. There were no sex significative differences.

Thus, effects of maternal separation seem to be persis- 
Table 3. Performances of a second generation of rat from depressed and anxious mothers in behavioral tests. Times are measured in seconds.

\begin{tabular}{|c|c|c|c|c|c|}
\hline \multirow[b]{2}{*}{ Parameter of behavioral test } & \multicolumn{2}{|c|}{ Control Group } & \multicolumn{2}{|c|}{ Experimental Group } & \multirow{2}{*}{$\mathrm{p}$} \\
\hline & Mean & Standard Deviation & Mean & Standard Deviation & \\
\hline Time of immobility (FST) & $\begin{array}{l}\text { J } 21.6 \\
+26.2\end{array}$ & $\begin{array}{l}13.2 \\
+4.08\end{array}$ & $\begin{array}{l}\text { o } 38 \\
060\end{array}$ & $\begin{array}{l}\text { ठ } 4.24 \\
\text { O } 7.54\end{array}$ & $\begin{array}{c}\delta 0.001<\mathrm{p}<0.01^{* *} \\
+\mathrm{p}<0.001^{* * *}\end{array}$ \\
\hline Number of entries in open arms (EPM) & $\begin{array}{l}\text { † } 5.8 \\
\text { † } 7.4\end{array}$ & $\begin{array}{l}\curvearrowright 0.83 \\
+2.07\end{array}$ & $\begin{array}{l}13 \\
+4.3\end{array}$ & $\begin{array}{l}\text { đ } 4.24 \\
+2.08\end{array}$ & 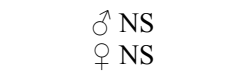 \\
\hline Total number of entries in all arms (EPM) & $\begin{array}{l}\text { ○े } 15.8 \\
\text { ○ } 16.4\end{array}$ & $\begin{array}{l}\text { Љ } 2.94 \\
\varnothing 2.07\end{array}$ & $\begin{array}{l}\text { § } 9 \\
+13.66\end{array}$ & $\begin{array}{l}\text { ○ } 8.48 \\
+0.8\end{array}$ & 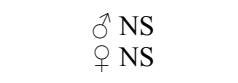 \\
\hline Time spent in central area (OF) & $\begin{array}{l}\text { ๖ } 91.2 \\
\text { ○ } 96\end{array}$ & $\begin{array}{l}\text { o } 11.03 \\
+6.55\end{array}$ & $\begin{array}{l}\text { 1) } 99 \\
+89.2\end{array}$ & $\begin{array}{l}\text { o } 5.65 \\
+17.83\end{array}$ & 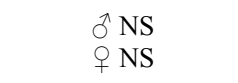 \\
\hline Number of returns in central area $(\mathrm{OF})$ & $\begin{array}{l}\text { } 111 \\
\text { ㅇ } 8.4\end{array}$ & $\begin{array}{l}\text { đo } 1.41 \\
\text { o } 1.94\end{array}$ & $\begin{array}{l}17.8 \\
\text { ○ } 9\end{array}$ & $\begin{array}{l}\text { đ } 1.48 \\
+22.64\end{array}$ & $\begin{array}{c}\delta 0.01<\mathrm{p}<0.05^{*} \\
\text { \& } \mathrm{NS}\end{array}$ \\
\hline Number of straightening (OF) & $\begin{array}{l}\uparrow 8.6 \\
+9\end{array}$ & $\begin{array}{l}\text { o } 2.6 \\
+1.22\end{array}$ & $\begin{array}{l}\text { 万 } 5.5 \\
+9.66\end{array}$ & $\begin{array}{l}\text { ○ } 0.7 \\
+\quad 1.52\end{array}$ & 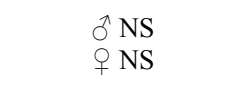 \\
\hline Number of excrements (OF) & $\begin{array}{l}\Im 0 \\
+0.2\end{array}$ & $\begin{array}{c}\text { ô } 0 \\
\text { ○ } 0.44\end{array}$ & $\begin{array}{l}\text { 万1 } 1 \\
+0.3\end{array}$ & 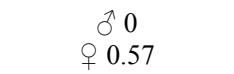 & $\begin{array}{l}\text { † } \mathrm{NS} \\
\text { o } \mathrm{NS}\end{array}$ \\
\hline
\end{tabular}

p: Probability; NS: Non significant; ${ }^{*}$ : Significant; ${ }^{* *}$ : Very significant; ${ }^{* * *}$ : Highly significant.

tent: when a rat's mother underwent this kind of stress, it transmitted its character of depression and anxiety to its descendants.

Changes in behavior may be led by hormones transmission during gestation, especially corticosterone [17]. The early environment manipulations have the ability to program HPA axis. The phenotype of HPA function following early manipulation depends on the timing and intensity of the manipulation, in addition to the gender of the fetus or neonate [18]. In our study, females develop high rates of depression compared to males. This indicates that the expression of the transmitted character takes place in a particular hormonal context.

Both in human and in animals, the vulnerability of females to mental illnesses and especially affective disorders has been well established $[19,20]$ and this epidemiological character is usually related to hormonal fluctuations that women underwent throughout their lives.

To explain the mechanism of the transmission of depression and anxiety from mothers to rat pups, SaavedraRodríguez and Feig [17] evoke three possible mechanisms: a genetic transmission, an epigenetic transmission and/or a lack of maternal care.

These findings support the idea that individual risk for psychiatric disorders that involve enhanced depression and/or anxiety may be dependent not only on the specific genes that are inherited from one's parents and on one's own experiences but also on the experiences of one's parents.

\section{Acknowledgements}

The authors would like to thank the CNRST (Morocco) for the financial support to this work. This work was also supported by GDRI Neurosciences (France, Morocco 2011-2014) and the European Neuromed project. Thanks to Dr. D. Boussaoud (French coordinator of GDRI) for support and encouragement.

\section{REFERENCES}

[1] F. P. Della, H. M. Abelaira, G. Z. Réus, A. R. Antunes, M. A. B. Dos Santos, G. Zappelinni, A. V. Steckert, F. Vuolo, L. S. Galant, F. Dal-Pizzol, F. Kapczinski and J. Quevedo, "Tianeptine Exerts Neuroprotective Effects in the Brain Tissue of Rats Exposed to the Chronic Stress Model Pharmacology," Biochemistry and Behavior, Vol. 103, No. 2, 2012, pp. 395-402. doi:10.1016/j.pbb.2012.09.018

[2] O. Kofman, "The Role of Prenatal Stress in the Etiology of Developmental Behavioural Disorders," Neuroscience \& Biobehavioral Reviews, Vol. 26, No. 4, 2002, pp. 457470. doi:10.1016/S0149-7634(02)00015-5

[3] U. Pauli-Pott, S. Friedel, A. Hinney and J. Hebebrand, "Serotonin Transporter Gene Polymorphism (5-HTTLPR), Environmental Conditions, and Developing Negative Emotionality and Fear in Early Childhood," Journal of Neural Transmission, Vol. 116, No. 4, pp. 503-512. doi:10.1007/s00702-008-0171-Z

[4] M. Durand, O. Berton, S. Aguere, L. Edno, I. Combourieu, P. Mormede and F. Chaouloff, "Effects of Repeated-Fluoxetine on Anxiety-Relatedbehaviours, Central Sero-Tonergic Systems, and the Corticotropic Axis in SHR and WKY Rats," Neuropharmacology, Vol. 38, 1999, pp. 893-907. doi:10.1016/S0028-3908(99)00009-X

[5] A. G. Nasselo, C. Machado, J. F. Bastos and L. Felicio, "Sudden Darkness Induces a High Activity-Lower Anxiety State in Male and Female Rats," Physiology \& Be- 
havior, 1998, Vol. 63, No. 3, pp. 451-454. doi:10.1016/S0031-9384(97)00462-9

[6] L. Meyer, J. Caston and A. Mensah-Nyagan, "Seasonal Variation of the Impact of a Stressful Procedure on Open Field Behaviour and Blood Corticosterone in Laboratory Mice," Behavioural Brain Research, Vol. 167, 2006, pp. 342-348. doi:10.1016/S0031- 9384(97)00462-9

[7] F. Clenet, E. Bouyon, M. Hasco and M. Bourin, "Light/ Dark Cycle Manipulation Influences Mice Behavior in the Elevated Plus Maze," Behavioural Brain Research, Vol. 166, 2006, pp. 140-149. doi:10.1016/j.bbr.2005.07.018

[8] S. Pellower, P. Chopin, S. E. File and M. Briley, "Validation of Open: Closed Arms Entries in an Elevated PlusMaze as a Measure of Anxiety in the Rat," Journal of Neuroscience Methods, Vol. 14, No. 3, 1985, pp. 149-167. doi:10.1016/0165-0270(85)90031-7

[9] R. D. Porsolt, G. Anton, N. Blavet and M. Jalfre, "Behavioural Despair in Rats: A New Model Sensitive to Antidepressant Treatments," European Journal of Pharmacology, Vol. 47, No. 4, 1978, pp. 379-391. doi:10.1016/0014-2999(78)90118-8

[10] M. L. Boccia, M. Razzoli, S. P. Vadlamudi, W. Trumbull, C. Caleffie and C. A. Pedersen, "Repeated Long Separations from Pups Produce Depression-Like Behavior in Rat Mothers," Psychoneuroendocrinology, Vol. 32, No. 1, 2007, pp. 65-71. doi:10.1016/j.psyneuen.2006.10.004

[11] M. Embree, V. Michopoulos, J. R. Votaw, R. J. Voll, J. Mun, J. S. Stehouwer, M. M. Goodman, M. E. Wilson and M. M. Sanchez, "The Relation Of Developmental Changes in Brain Serotonin Transporter (5htt) and 5HT1a Receptor Binding to Emotional Behavior in Female Rhesus Monkeys: Effects of Social Status and 5htt Genotype," Neuroscience, Vol. 228, 2013, pp. 83-100. doi:10.1016/i.neuroscience.2012.10.016

[12] V. L. Kallen, J. H. Tulen, E. M. Utens, P. D. Treffers, F. H. De Jong and R. F. Ferdinand, "Associations between HPA Axis Functioning and Level of Anxiety in Children and Adolescents with an Anxiety Disorder," Depress Anxiety, Vol. 25, No. 2, 2008, pp. 131-141. doi:10.1002/da.20287

[13] A. Graziottin and A. Serafini, "Depression and the Meno- pause: Why Antidepressants Are Not Enough?" Menopause International, Vol. 15, No. 2, 2009, pp. 76-81. doi:10.1258/mi.2009.009021

[14] N. C. Vamvakopoulos and G. P. Chrousos, "Evidence of Direct Estrogen Regulation of Human Corticotropin-Releasing Hormone Gene Expression: Potential Implications for the Sexual Dimorphism of the Stress Response and Immune/Inflammatory Reaction," Journal of Clinical Investigation, Vol. 92, No. 4, 1993, pp. 1896-1902. doi:10.1172/JCI116782

[15] Z. Sheng, A. Yanai, R. Fujinaga, J. Kawano, M. Tanaka and Y. Watanabe, "Gonadal and Adrenal Effects on the Glucocorticoid Receptor in the Rat Hippocampus, with Special Reference to Regulation by Estrogen from an Immunohistochemical View-Point," Neuroscience Research, Vol. 46, No. 2, 2003, pp. 205-218. doi:10.1016/S0168-0102(03)00056-7

[16] D. F. Swaab, "Neuropeptides in Hypothalamic Neuronal Disorders," International Review of Cytology, Vol. 240, 2004, pp. 305-375. doi: 10.1016/S0074- 7696(04)40003-5

[17] L. Saavedra-Rodríguez and L. A. Feig, "Chronic Social Instability Induces Anxiety and Defective Social Interactions across Generations," Biological Psychiatry, Vol. 73, No. 1, 2012, pp. 44-53. doi:10.1016/j.biopsych.2012.06.035

[18] S. G. Matthews, "Early Programming of the HypothalamoPituitary-Adrenal Axis," Trends in Endocrinology \& Metabolism, Vol. 13, No. 9, 2002, pp. 373-380. doi:10.1016/S1043-2760(02)00690-2

[19] S. N. Vigod and D. E. Stewart, "Emergent Research in the Cause of Mental Illness in Women across the Lifespan," Current Opinion in Psychiatry, Vol. 22, 2009, pp. 396-400.

[20] R. Bousalham, B. Benazzouz, A. El Hessni, A. Ouichou, H. El Kebir, Kh. Boudiaf and A. Mesfioui, "Profil Rétrospectif des Troubles Psychiatriques Dans la Région du Gharb Cherarda Béni Hsen (Maroc)," European Journal of Scientific Research, Vol. 93, 2012, pp. 553-560. 